\title{
Homer 1a Gene Expression Modulation by Antipsychotic Drugs: Involvement of the Glutamate Metabotropic System and Effects of D-Cycloserine
}

Daniela Polese, M.D., Antonella Amato de Serpis, M.D., Alberto Ambesi-Impiombato, M.D., Giovanni Muscettola, M.D., and Andrea de Bartolomeis, M.D., Ph.D.

$N$-methyl-D-aspartate receptor hypofunction has been suggested to play a role in the pathophysiology of schizophrenia. New glutamatergic mechanisms involving metabotropic receptors have been recently proposed to further expand this hypothesis. "Homer" is a family of postsynaptic density proteins functionally and physically attached to glutamate metabotropic receptors. We investigated the activation of the early gene form of Homer after acute treatment with typical or atypical antipsychotic drugs alone or with the adjunction of D-cycloserine. This activation was compared with that of $c$-fos, considered a putative molecular marker of brain regions activated by antipsychotics. Male Sprague-Dawley rats were treated intraperitoneally with haloperidol $(0.8 \mathrm{mg} / \mathrm{Kg})$ or clozapine $(15 \mathrm{mg} / \mathrm{Kg})$ alone or with the adjunction of D-cycloserine $(20 \mathrm{mg} / \mathrm{Kg})$. Rats were sacrificed ninety minutes after injection and the brains were processed for quantitative in situ hybridization histochemistry. Haloperidol induced a statistically significant increase of Homer both in caudate- putamen and nucleus accumbens compared with controls; clozapine induced Homer significantly only in the accumbens. The adjunction of D-cycloserine attenuated the haloperidol-induced increase of Homer expression in caudate-putamen and nucleus accumbens and attenuated the clozapine-induced increase in the accumbens. The c-fos gene expression was potently induced by haloperidol in caudate-putamen and nucleus accumbens, and by clozapine only in the accumbens. The adjunction of D-cycloserine enhanced c-fos expression only for clozapine in both regions of the forebrain. These results demonstrate a differential involvement of glutamatergic metabotropic system in gene expression modulation induced by typical or atypical antipsychotic drugs and may suggest new molecular basis for the augmentation strategy by a glycine site partial agonist.

[Neuropsychopharmacology 27:906-913, 2002] (C) 2002 American College of Neuropsychopharmacology. Published by Elsevier Science Inc.
From the Department of Neuroscience and Behavioral Sciences, Laboratory of Molecular Psychiatry and Psychopharmacotherapy, Section of Psychiatry, University School of Medicine "Federico II", Naples, Italy.

Address correspondence to: Andrea de Bartolomeis, M.D., Ph.D. Department of Neuroscience and Behavioral Sciences, Laboratory of Molecular Psychiatry and Psychopharmacotherapy, Section of
Psychiatry, University of Naples Medical School "Federico II", Edificio 18, Via Pansini 5 80131, Naples, Italy. Tel.: +39 081746 3673; Fax: +39081 746 2378; E-mail: adebart@tiscalinet.it

Received October 23, 2001; revised April 13, 2002; accepted May 10, 2002.

Online publication: 5/14/02 at www.acnp.org/citations / Npp051402306. 
KEY WORDS: Antipsychotic agents; Augmentation; $D$-cycloserine; RNA messenger; In situ hybridization; Glutamate

The glutamatergic hypothesis of psychotic disorders postulates a cortical and subcortical N-methyl-D-aspartate (NMDA) Receptor Hypofunction (NRH) and a subcortical hyperdopaminergy (Breier et al. 1998; Olney et al. 1999). New glutamatergic mechanisms should be taken into account in order to investigate the molecular basis of dopamine-glutamate interactions in the pathophysiology of psychosis. Indeed, the study of the glutamatergic transmission has focused on the role of metabotropic receptors (Moghaddam and Adams 1998), post synaptic density proteins (de Bartolomeis et al. 2002) and glycine modulation of NMDA receptors (Heresco-Levy 2000). These molecular mechanisms have suggested new pharmacological strategies such as the adjunction of D-cycloserine to antipsychotic drugs (Goff et al. 1999a,b).

D-cycloserine is a partial agonist at the strychnineinsensitive glycine site of the NMDA receptor complex with approximately $40 \%$ to $60 \%$ activity compared with the endogenous ligand (Goff et al. 1999b). D-cycloserine at the dose of $50 \mathrm{mg}$ /day has been demonstrated to improve primary negative symptoms in patients with schizophrenia when added to conventional neuroleptics (Goff et al. 1999b) but not to clozapine (Goff et al. 1996, 1999a). D-cycloserine's therapeutic effects probably result from a relative agonist rather than antagonist action at the glycine modulatory site (Goff et al. 1999b) since the full agonist glycine has been shown to improve negative symptoms in a similar manner (Heresco-Levy et al. 1996; Javitt et al. 1994). The findings of therapeutic effects on negative symptoms of schizophrenia obtained by NMDA receptor potentiation are consistent with the NRH hypothesis of psychosis. The drug-induced NRH model has been considered the most specific psychotomimetic drug model of schizophrenia for its ability to reproduce psychotic-like negative symptoms in healthy humans (Malhotra et al. 1996). In contrast, it has been shown that at doses of 100 $\mathrm{mg} /$ day or $250 \mathrm{mg} /$ day D-cycloserine had no effect on negative symptoms and worsened positive symptoms of psychosis. This may be explained by the evidence that at higher concentrations D-cycloserine acts as an antagonist rather than a partial agonist at the glycine site (Cascella et al. 1994; van Berckel et al. 1999). Finally, it has been suggested that glycine may be less effective when combined to clozapine than when combined to conventional neuroleptics (Evins et al. 2000).

Homer is a postsynaptic density protein localized at excitatory synapses that interacts with the C-terminal intracellular tail of group 1 metabotropic glutamate receptors (mGluRs) through a PDZ-like domain (Brakeman et al. 1997; Kato et al. 1998). Some PDZ domains (present in PSD-95, Dlg, and ZO-1/2 proteins) have been shown to bind C-terminal polypeptides, whereas others appear to bind internal (non-C-terminal) polypeptides. Homer is thought to have a direct role in neuronal plasticity since it regulates the cytoskeletal attachment and clustering of group 1 mGluRs (Brakeman et al. 1997) coupling them physically and functionally to the intracellular IP3 receptors, thus modulating the specific phosphoinositide pathway. In detail, Homer 1a protein functions as a "dominant negative" in that its increase displaces the constitutively expressed Homers and disrupts group $1 \mathrm{mGluRs}$ clustering (Tu et al. 1998). We previously described a differential effect of typical (haloperidol) or atypical (olanzapine) antipsychotics on Homer gene expression (de Bartolomeis et al. 2002).

Several immediate early genes (IEGs), such as c-fos (Hiroi and Graybiel 1996; Semba et al. 1999) have been demonstrated to be induced differentially by typical and atypical antipsychotics. Also, they are a potential molecular tool for the screening of the pharmacological profile of antipsychotic compounds (MacGibbon et al. 1994). While these effects may be relevant as a metabolic marker of antipsychotic action it needs to be emphasized that the role of fos family proteins in the mechanism of action of antipsychotics is probably more complex, specially with regards to chronic treatments. Inferences regarding the final target genes activated by IEGs and their direct impact on neuronal plasticity may be difficult to draw.

In the present study, we investigated the effects of the acute treatment with typical (haloperidol) or atypical (clozapine) antipsychotic drugs on the gene expression of Homer 1a and c-fos in the striatum and nucleus accumbens by means of quantitative in situ hybridization histochemistry (ISHH). Furthermore, we studied the impact of D-cycloserine adjunction to haloperidol or clozapine on the pattern of gene expression, in the attempt to better characterize the putative molecular substrate of antipsychotics augmentation strategy in an animal model.

\section{MATERIALS AND METHODS}

\section{Animals and Treatments}

Male Sprague Dawley rats weighing $\sim 250 \mathrm{~g}$ were housed and adapted to human handling in a temperature and humidity controlled colony room with $12 / 12 \mathrm{~h}$ light/ dark cycle (lights on from 6 a.m. to 6 p.m.) with ad libitum access to lab chow and water. On the day of the experiment rats were randomly assigned to one of the following six treatment groups: (1) saline $(0.9 \% \mathrm{NaCl})$ plus saline (SAL); (2) saline plus haloperidol $0.8 \mathrm{mg} / \mathrm{kg}$ (HAL); (3) saline plus clozapine $15 \mathrm{mg} / \mathrm{kg}$ (CLO); (4) saline plus D-cycloserine $20 \mathrm{mg} / \mathrm{kg}$ (DCS); (5) haloperidol $0.8 \mathrm{mg} / \mathrm{kg}$ plus D-cycloserine $20 \mathrm{mg} / \mathrm{kg}$ (HAL+DCS); and (6) clozapine $15 \mathrm{mg} / \mathrm{kg}$ plus D-cycloserine $20 \mathrm{mg} / \mathrm{kg}$ (CLO+DCS). Each animal received 
two $250 \mu$ injections intraperitoneally. The animals were sacrificed by decapitation $90 \mathrm{~min}$ after the second injection. The brains were rapidly removed, frozen on dry ice, and stored at $-70^{\circ} \mathrm{C}$ prior to sectioning. All procedures were conducted in accordance with the NIH Guide for Care and Use of Laboratory Animals and were approved by the local Animal Care and Use Committee.

\section{Synthetic Oligodeoxyribonucleotides}

The Homer 1a probe was a 48-base oligodeoxyribonucleotide complementary to bases 1073-1120 of the rat Homer 1a mRNA (GenBank Accession U92079). The c-fos probe was a 48-base pair oligodeoxyribonucleotide complementary to bases 270-319 of the rat c-fos mRNA (Curran et al. 1987; Merchant and Dorsa 1993). The specificity of the antisense probe signal was assessed using the corresponding sense oligodeoxyribonucleotides in the same hybridization and stringency conditions. No autoradiographic signal was detected in any of the regions in which the antisense probe yielded positive results. Moreover, the same neuroanatomical signal distribution was observed for both probes in previous ISHH experiments (de Bartolomeis et al. 2002; Merchant and Dorsa 1993).

\section{Probe Labeling}

The probes were labeled at the $3^{\prime}$ end with $0.4-0.6 \times 10^{6}$ cpm $\left[\alpha^{35} \mathrm{~S}\right]$ dATP $(>1000 \mathrm{Ci} / \mathrm{mmol}$, Amersham Pharmacia Biotech), terminal deoxynucleotidyl transferase (15 units/ml) (Roche), and tailing buffer. The unincorporated nucleotides were separated from radiolabeled DNA using Sephadex G-50 chromatographic columns (Amersham Pharmacia Biotech). The procedure for in situ hybridization histochemistry was taken from several standard published protocols (Austin et al. 1992; de Bartolomeis et al. 1994; Young et al. 1986).

\section{In Situ Hybridization Histochemistry}

Frozen $12 \mu \mathrm{m}$ sections were cut on a cryostat at $-19^{\circ} \mathrm{C}$ at approximately bregma $1.60 \mathrm{~mm}$ forebrain level, using plate 12 of the rat brain atlas of Paxinos and Watson (1986) as an anatomical reference; sections were mounted onto gelatin-coated slides, and stored at $-80^{\circ} \mathrm{C}$ for subsequent processing. Prior to hybridization, the sections were fixed in $1.5 \%$ formaldehyde in $0.12 \mathrm{M}$ sodium-phosphate buffered saline (PBS, $\mathrm{pH} 7.4$ ), quickly rinsed three times with $1 \times$ PBS, and placed in $0.25 \%$ acetic anhydride in $0.1 \mathrm{M}$ triethanolamine $/ 0.9 \% \mathrm{NaCl}, \mathrm{pH} 8.0$, for $10 \mathrm{~min}$. Next, the sections were dehydrated in $70 \%, 80 \%, 90 \%$, and $100 \%$ ethanol, delipidated in chloroform for $5 \mathrm{~min}$, rinsed again in 100\% and 95\% ethanol and air dried. Sections were hybridized with $0.4-0.6 \times 10^{6} \mathrm{cpm}$ of radiolabeled oligonucleotide in buffer containing $50 \%$ formamide, $600 \mathrm{mM} \mathrm{NaCl}, 80 \mathrm{mM}$ Tris- $\mathrm{HCl}$ (pH 7.5), $4 \mathrm{mM}$
EDTA, $0.1 \%$ pyrophosphate, $0.2 \mathrm{mg} / \mathrm{ml}$ heparin sulfate, and $10 \%$ dextran sulfate. Incubations were carried out at $37^{\circ} \mathrm{C}$ in a humid chamber for $20 \mathrm{~h}$. After hybridization the sections were washed $4 \times 15 \mathrm{~min}$ in $2 \times \mathrm{SSC} / 50 \%$ formamide at $40^{\circ} \mathrm{C}$, followed by two 30-min washes with $1 \times$ SSC at $40^{\circ} \mathrm{C}$. The slides were rapidly rinsed in distilled water and then in $70 \%$ ethanol. The sections were dried and exposed to Biomax MR X-ray film (Kodak Scientific Imaging Film) for 14-30 days. The optimal time of exposure was chosen to maximize signal to noise ratio while preventing optical density from approaching the limits of saturation. ${ }^{14} \mathrm{C}$ standard sections with several known amounts of radioactivity cross-calibrated with ${ }^{35} \mathrm{~S}$ standards were co-exposed with the samples.

\section{Image Analysis}

The quantitation of the autoradiographic signal was performed using a computerized image analysis system including: a light box (Northern Light) and a CCD camera, an Apple PowerPC, and NIH Image 1.62 software (W. Rasband, NIMH, Bethesda, MD). Sections were quantitated blind to the treatment conditions. In order to test for inter-observer reliability an independent quantitation was performed by a second investigator. Only quantitatively comparable results, in terms of consistency of any statistically significant effect, obtained by the two investigators were considered reliable. For each experimental group three to five slides were analyzed. Each slide contained 2-4 adjacent sections of a single animal. Care was taken to select identical anatomical levels of treated and control sections using thionin-stained reference slides. Quantitative comparisons among different experimental groups were performed using images from hybridized sections exposed on the same sheet of X-ray film. Regions of interest (ROI) were outlined on digitized autoradiograms and the transmittance was measured using NIH image software. Forebrain sections were analyzed in the caudate-putamen and nucleus accumbens regions. The caudate-putamen dorsolateral subregion was outlined and measured using an oval template of $0.70 \mathrm{~mm} \times 1.17 \mathrm{~mm}$ (Figure 1). A region of the nucleus accumbens was measured using an oval template of $0.60 \mathrm{~mm} \times 0.72 \mathrm{~mm}$ (Figure 1).

\section{Data Analysis}

Measurements of optical density within ROIs were then converted into "relative dpm" by a calibration curve based on the standard scale co-exposed to the sections. For this purpose a "best fit" third-degree polynomial was used. For each animal measurements from the $2-4$ adjacent sections were averaged. The data were analyzed for treatment effects by a 1-way Analysis of Variance (ANOVA). Fisher's Protected LSD post hoc test was used to determine the locus of effects in any significant ANOVA. 


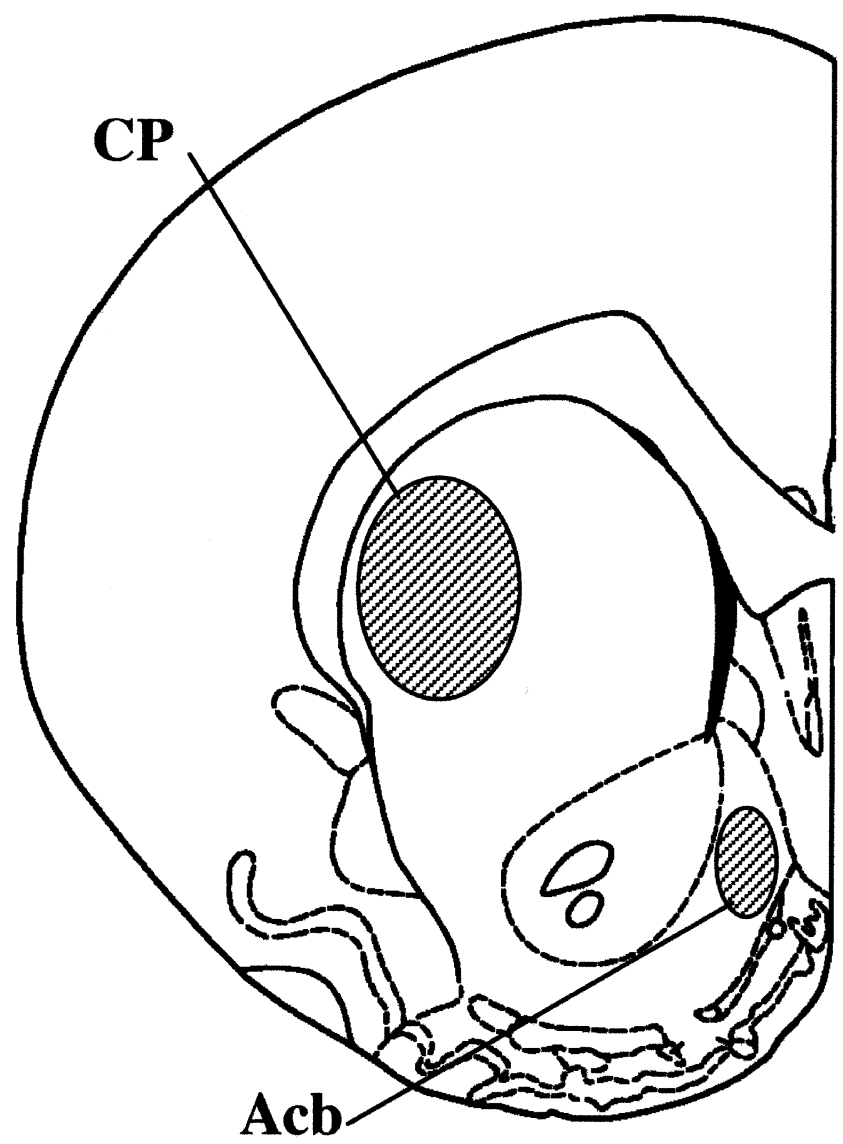

Figure 1. Diagram of rat forebrain section with regions of interest (ROIs) quantitated on film autoradiograms. $\mathrm{CP}=$ caudate-putamen; $\mathrm{Acb}=$ nucleus accumbens (modified from Paxinos and Watson 1986).

\section{RESULTS}

\section{Homer 1a}

Homer 1a gene expression was detected in several forebrain regions of the control animals. The signal was homogeneously distributed throughout the cerebral cortex, and was present in caudate-putamen, nucleus accumbens, and the islands of Calleja, consistently with previous reports (de Bartolomeis et al. 2002). Statistically significant differences in Homer 1a gene expression (Figure 2) have been found among experimental groups in the dorsolateral subregion of caudate-putamen (Figure 3) and in the nucleus accumbens (Figure 4).

In caudate-putamen the following statistically significant differences were found: HAL greater than SAL, DCS and CLO+DCS. In the same region, CLO was significantly greater than DCS. Moreover, HAL+DCS showed a statistically significant increase vs. DCS (ANOVA, $p=.0072$ ).

In the nucleus accumbens a statistically significant Homer 1a mRNA increase was found in HAL group compared with SAL, HAL+DCS, CLO+DCS and in CLO compared with SAL (ANOVA, $p=.0143$ ).

c-fos

In the saline group the c-fos signal was homogeneously distributed throughout the cerebral cortex and the islands of Calleja, and a low signal was detected in the caudate-putamen and the nucleus accumbens.

In the dorsolateral subregion of caudate-putamen, a statistically significant increase of c-fos gene expression (Figure 5 and Figure 6) was detected under both haloperidol treatments, i.e. HAL and HAL+DCS vs. SAL, CLO, DCS and CLO+DCS; moreover, CLO+DCS was significantly greater than baseline (ANOVA, $p<.0001$ ).

In the nucleus accumbens, the densitometric analysis of autoradiographic images showed a statistically significant increase of c-fos mRNA expression (Figure 5 and Figure 7) after all the antipsychotic treatments, both with and without D-cycloserine adjunction. In this region, the following differences were statistically significant: HAL greater than SAL and than DCS; CLO greater than SAL; CLO+DCS greater than SAL, CLO, DCS; and finally HAL+DCS greater than SAL, HAL, CLO, DCS and CLO+DCS (ANOVA, $p<.0001$ ).

\section{DISCUSSION}

Based on previous animal studies, our dosage of D-cycloserine of $20 \mathrm{mg} / \mathrm{kg}$ can be predicted to exert agonistic effects on the glycine site of the NMDA receptor. This dosage has been shown to facilitate performance on learning tasks in rodents, a property attributed to NMDA receptor potentiation (Andersen et al. 2002; Baran et al. 1995; Depoortere et al. 1999; Monahan et al. 1989). Antagonistic effects of D-cycloserine such as its anticonvulsive properties are associated to much higher doses (160-320 mg/ kg) in rodents (Baran et al. 1995; Loscher et al. 1994; Wlaz et al. 1994). It is conceivable that the D-cycloserine dose of $20 \mathrm{mg} / \mathrm{kg}$ in rats exerts an agonistic effect similarly to the dosage proven to be effective in adjunction to haloperidol in humans. Interestingly, we previously found that quantitatively comparable results of Homerla expression in caudate-putamen are obtained using D-cycloserine at a dose of either of $20 \mathrm{mg} / \mathrm{kg}$ or $100 \mathrm{mg} / \mathrm{kg}$ in adjunction to haloperidol (unpublished data). This may suggest that even higher doses (at least up to $100 \mathrm{mg} / \mathrm{kg}$ ) may exert agonistic effects in our paradigm. However, caution must be used when interpreting our findings in terms of reproduction of pharmacological effects reported in clinical trials, as effects on psychotic symptoms occur over a period of weeks, whereas our study is based on acute treatments. While further studies using chronic treatments will be 

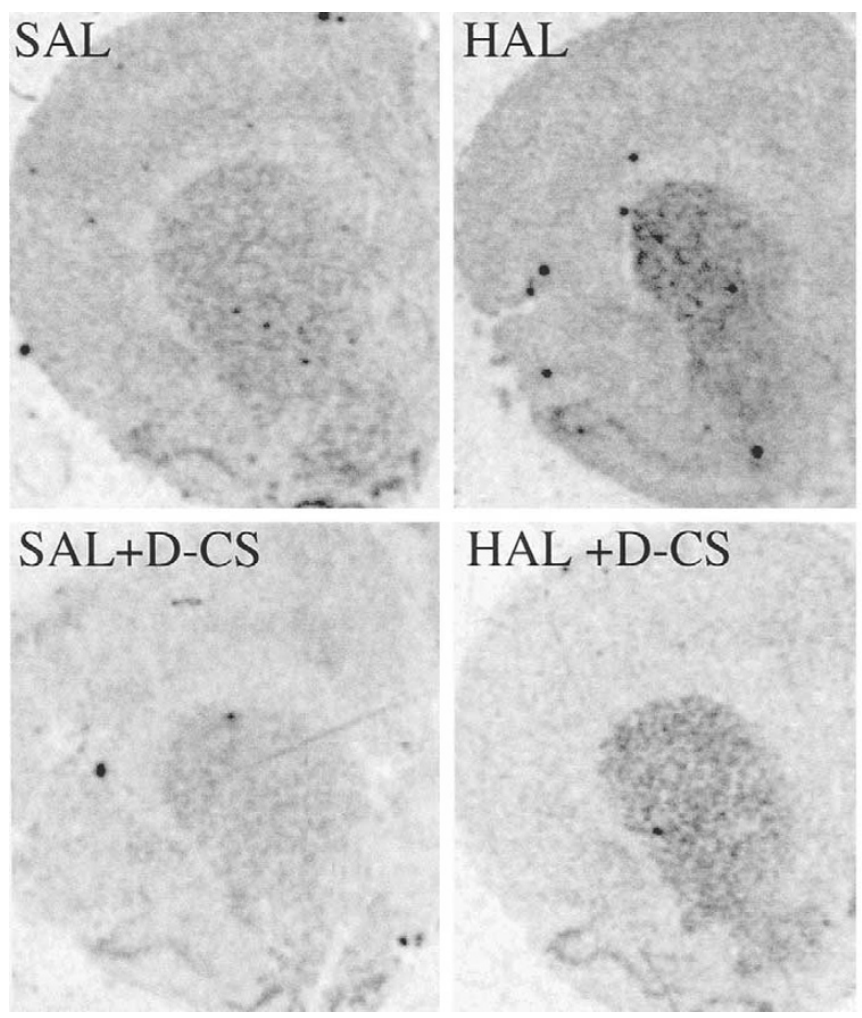
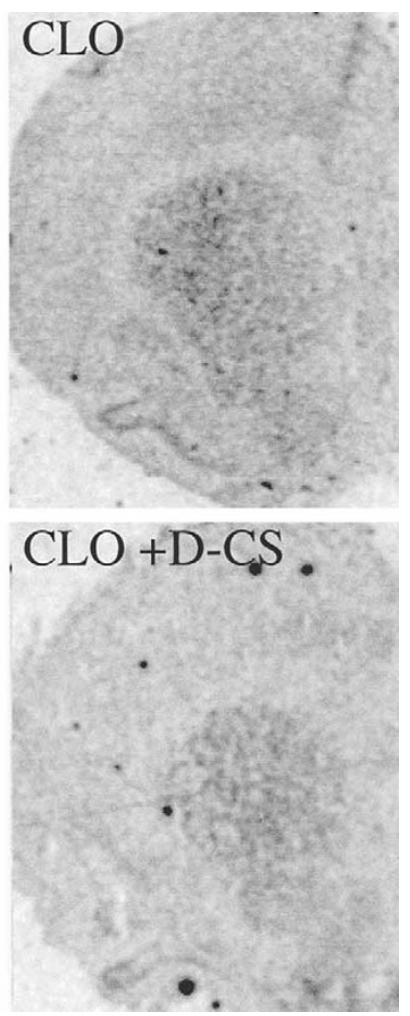

Figure 2. Autoradiograms of rat forebrain sections hybridized with Homer 1a probe. The comparison of treated groups vs. saline shows a remarkable signal increase of haloperidol and clozapine groups in caudate-putamen and nucleus accumbens. Moreover, the signal appears less intense when D-cycloserine is added to haloperidol and clozapine, in the same regions. of great interest, our findings may represent an important first step in the understanding of the molecular mechanisms of D-cycloserine augmentation strategy. The acute treatment used in the present study is further justified by our specific focus on the modulation of immediate early genes as Homer 1a and c-fos.

The results show that typical or atypical antipsychotics may modulate differentially the gene expression of the marker of the glutamatergic system Homer 1a, and

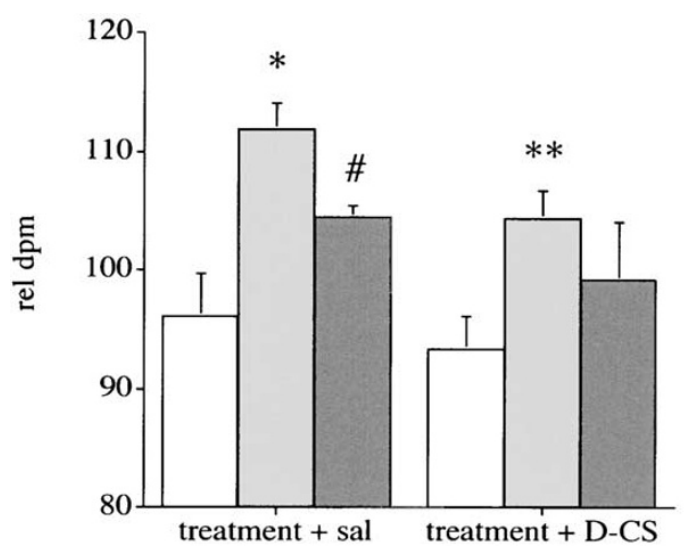

SAL

口 HAL

$\square$ CLO

Figure 3. Homer mRNA levels in caudate-putamen quantitated by densitometry of in situ hybridization histochemistry autoradiograms and expressed in "relative dpm". ANOVA: $p=.0072$. Fischer's Protected LSD post hoc test: *HAL vs. SAL, DCS and CLO+DCS; ${ }^{* * H A L+D C S ~ v s . ~ D C S ; ~ \# C L O ~ v s . ~ D C S . ~}$ of the IEG c-fos. The adjunction of D-cycloserine produced relevant effects on Homer and c-fos gene expression. Homer 1a mRNA levels in caudate-putamen are significantly increased by haloperidol treatment compared with DCS and CLO+DCS but not to treatment with clozapine alone (Figure 3). This finding suggests that D-cycloserine, when added to clozapine, attenuates clozapine-induced Homer 1a increase vs. DCS. More-

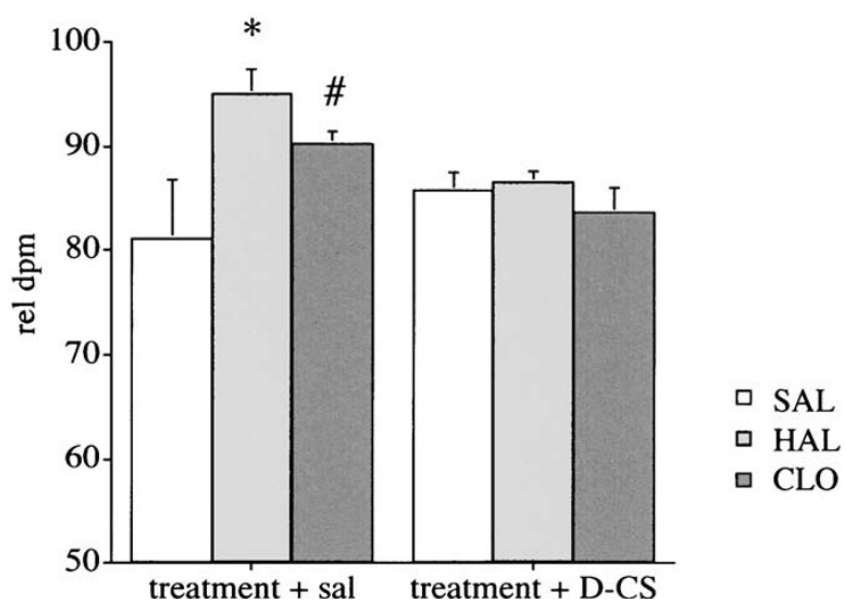

Figure 4. Homer mRNA levels in nucleus accumbens quantitated by densitometry of In Situ Hybridization Histochemistry autoradiograms and expressed in "relative dpm". ANOVA: $p=.0143$. Fischer's Protected LSD post hoc test: *HAL vs. SAL, HAL+DCS and CLO+DCS; \#CLO vs. SAL. 


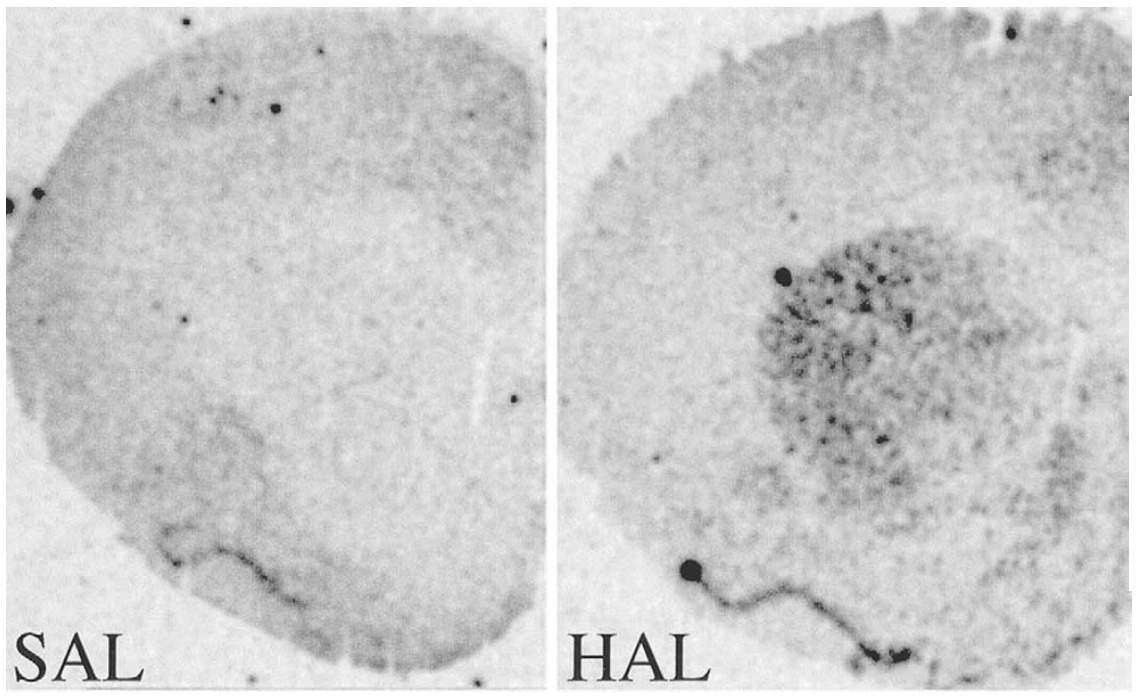

Figure 5. Autoradiographic images of rat forebrain sections hybridized with c-fos probe in saline and haloperidol treated groups. In saline control group, the signal is homogeneously distributed throughout the cerebral cortex and the islands of Calleja, but not in caudateputamen and nucleus accumbens. The comparison of the two images clearly shows the c-fos induction in caudateputamen and nucleus accumbens by haloperidol treatment. over, the clozapine treated group showed a statistically significant increase vs. DCS but not vs. SAL, and the HAL+DCS group also showed an increased signal compared with DCS group but not to SAL. Both these observations may be explained by the negative trend of the D-cycloserine group. It can also be observed that the adjunction of D-cycloserine to haloperidol attenuates the haloperidol induced Homer 1a increase, as HAL is significantly greater than SAL whereas HAL+DCS is not. In fact, HAL+DCS is reduced as compared with HAL, although this difference is not statistically significant. These effects seem to be neuroanatomically specific to caudate-putamen. At the molecular level, considering that Homer 1a functions as a "dominant negative" it can be predicted that the Homer 1a decrease by D-cycloserine

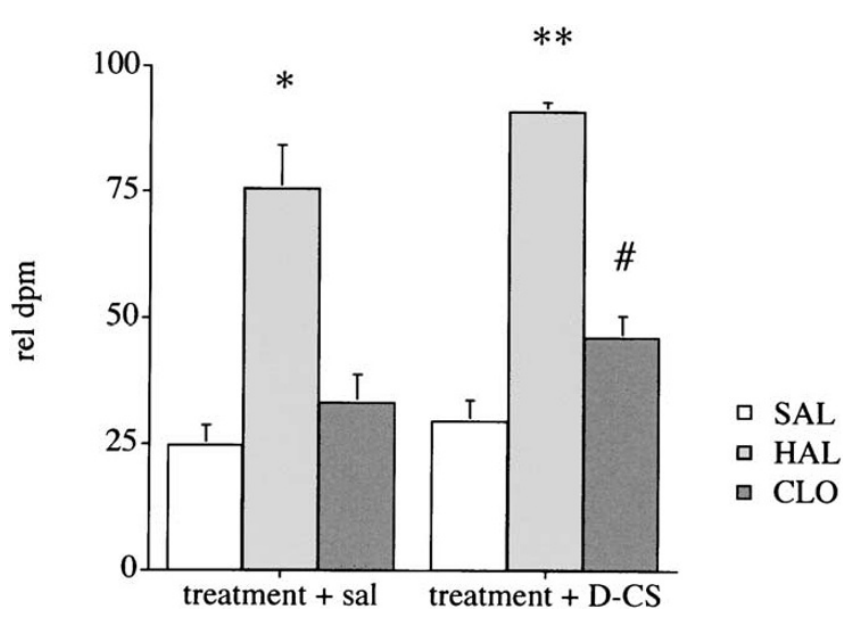

Figure 6. c-fos mRNA levels in caudate-putamen quantitated by densitometry of in situ hybridization histochemistry autoradiograms and expressed in "relative dpm". ANOVA: $p<.0001$. Fischer's Protected LSD post hoc test: ${ }^{*} \mathrm{HAL}$ vs. SAL, DCS, CLO and CLO+DCS; ${ }^{* *} \mathrm{HAL}+\mathrm{DCS}$ vs. SAL, DCS, CLO and CLO+DCS; \#CLO+DCS vs. SAL. augmentation determines a relative increase of mGluR clustering. This could be interpreted as a mechanism of metabotropic glutamatergic enhancement by a partial agonism at glycine site of NMDA receptor in subcortical neurons receiving cortical glutamatergic inputs.

In the nucleus accumbens, both antipsychotics significantly increased Homer 1a gene expression as compared with the saline group (Figure 4). This antipsychotic induced effect is abolished when the three D-cycloserine treated groups (DCS, HAL+DCS and CLO+DCS) are compared. Remarkably, HAL+DCS is significantly reduced as compared with HAL. So it

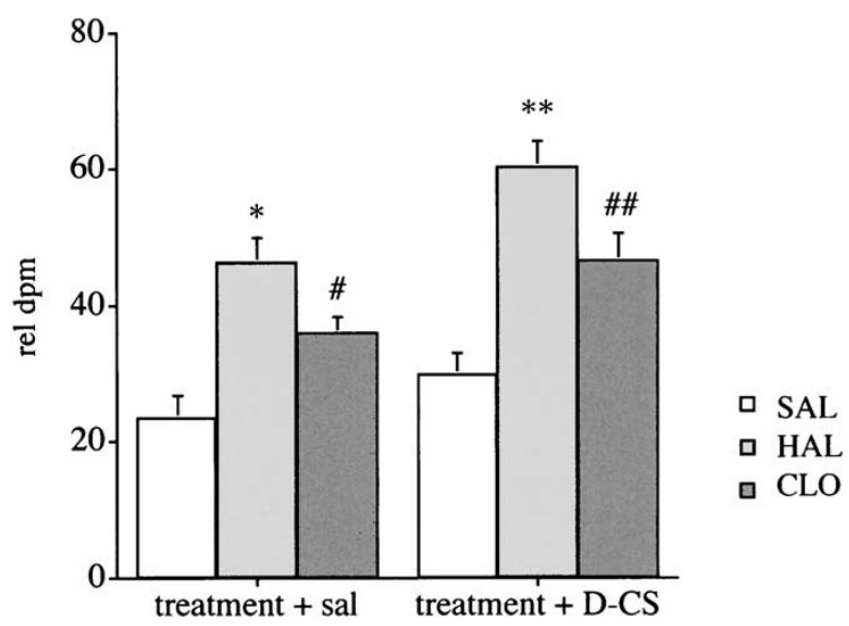

Figure 7. c-fos mRNA levels in nucleus accumbens quantitated by densitometry of In Situ Hybridization Histochemistry autoradiograms and expressed in "relative dpm". ANOVA analysis of variance test detected significant variations among the experimental groups $(p<.0001)$. Fischer's Protected LSD post hoc test showed the following statistically significant differences: *HAL vs. SAL and DCS; ${ }^{* *} \mathrm{HAL}+\mathrm{DCS}$ vs. SAL, DCS, CLO and CLO+DCS; \#CLO vs. SAL; \#\#CLO+DCS vs. SAL, CLO and DCS. 
seems that D-cycloserine negatively modulates Homer 1a gene expression when added to haloperidol and in a non-significant manner, when added to clozapine.

The discrete effect of the adjunction of D-cycloserine to haloperidol on Homer gene expression could underlie a limbic-specific activity of this drug association. Indeed, the signal decrease (HAL > HAL+DCS) is statistically significant in the nucleus accumbens, which is largely associated with limbic function, but not in the caudate-putamen, which is characteristically involved in motor control.

At the molecular level, the relevant role of Homer in the regulation of glutamate receptor clustering, their physical proximity, as well as the recent demonstrations of their ability to interact at the synapse and to modulate NMDA receptor function (Naisbitt et al. 1999) must be considered. The results of the present study suggest that D-cycloserine, added to antipsychotic drugs, may be involved in the modulation of neuronal plasticity and may functionally affect the postsynaptic density, which could be involved in the antipsychotics mechanism of action.

Finally, the IEG c-fos also proved to be differentially modulated by the different acute treatments. A differential induction of c-fos gene expression by typical or atypical antipsychotics has been demonstrated in several acute studies by independent reports (Hiroi and Graybiel 1996; Semba et al. 1999). Previous studies show that c-fos immuroreactivity is downregulated in the caudate-putamen after chronic treatment by haloperidol and clozapine but not by metoclopramide. In contrast, FosB-like immunoreactivity is upregulated after chronic administration of haloperidol but not clozapine (Hiroi and Graybiel 1996). All together these data point out that acute and chronic administration of antipsychotics may exert relevant differential effects on IEG induction and this observation needs to be considered when interpreting our results. In our acute paradigm, both haloperidol treatments, either alone or with D-cycloserine, potently induce its expression in the caudate-putamen (Figure 6). The atypical antipsychotic clozapine did not induce c-fos in this region unless DCS was added. The CLO+DCS induced c-fos expression was significantly higher than SAL, although it was at the same time significantly lower than both the HAL treatments. In the nucleus accumbens (Figure 7), c-fos mRNA was induced by both haloperidol and clozapine and the adjunction of D-cycloserine proportionally enhanced this induction. The c-fos mRNA induction pattern in both striatum and accumbens by haloperidol and clozapine that we observed is consistent with previous studies of c-fos mapping after treatment with typical or atypical antipsychotics (Guo et al. 1995; MacGibbon et al. 1994; Robertson and Fibiger 1992; Robertson et al. 1994). Those studies point out that both haloperidol and clozapine induce c-fos expression in nucleus accumbens, whereas haloperidol but not clozapine increases c-fos in the striatum. The differential D-cycloserine effect in the striatum may prove to better characterize the index of "atypicality" based on antipsychotic-induced c-fos expression pattern in the striatum (Robertson et al. 1994). Our findings may prove useful in the preclinical characterization of new antipsychotics and possibly in predicting clinical efficacy of associations of new antipsychotics with D-cycloserine. However, in order to draw more precise correlations to the efficacy of antipsychotic augmentation therapy on the negative symptoms of psychotic disorders, new experiments using different doses of D-cycloserine and chronic treatments will be a useful means of further investigation.

\section{REFERENCES}

Andersen JM, Lindberg V, Myhrer T (2002): Effects of scopolamine and D-cycloserine on non-spatial reference memory in rats. Behav Brain Res 129:211-216

Austin MC, Schultzberg M, Abbott LC, Montpied P, Evers JR, Paul SM, Crawley JN (1992): Expression of tyrosine hydroxylase in cerebellar Purkinje neurons of the mutant tottering and leaner mouse. Brain Res Mol Brain Res 15:227-240

Baran H, Gramer M, Loscher W (1995): Alterations in plasma and brain amino acids after administration of the glycine/NMDA receptor partial agonist, D-cycloserine, to mice and rats. Eur J Pharmacol 273:197-201

Brakeman PR, Lanahan AA, O'Brien R, Roche K, Barnes CA, Huganir RL, Worley PF (1997): Homer: a protein that selectively binds metabotropic glutamate receptors. Nature 386:284-288

Breier A, Adler CM, Weisenfeld N, Su TP, Elman I, Picken L, Malhotra AK, Pickar D (1998): Effects of NMDA antagonism on striatal dopamine release in healthy subjects: application of a novel PET approach. Synapse 29:142-147

Cascella NG, Macciardi F, Cavallini C, Smeraldi E (1994): d-cycloserine adjuvant therapy to conventional neuroleptic treatment in schizophrenia: an open-label study. J Neural Transm Gen Sect 95:105-111

Curran T, Gordon MB, Rubino KL, Sambucetti LC (1987): Isolation and characterization of the c-fos(rat) cDNA and analysis of post-translational modification in vitro. Oncogene 2:79-84

de Bartolomeis A, Aloj L, Ambesi-Impiombato A, Bravi D, Caraco C, Muscettola G, Barone P (2002): Acute administration of antipsychotics modulates Homer striatal gene expression differentially. Brain Res Mol Brain Res 98:124-129

de Bartolomeis A, Austin MC, Goodwin GA, Spear LP, Pickar D, Crawley JN (1994): Dopaminergic and peptidergic mRNA levels in juvenile rat brain after prenatal cocaine treatment. Brain Res Mol Brain Res 21:321-332

Depoortere R, Perrault G, Sanger DJ (1999): Prepulse inhibition of the startle reflex in rats: effects of compounds acting at various sites on the NMDA receptor complex. Behav Pharmacol 10:51-62

Evins AE, Fitzgerald SM, Wine L, Rosselli R, Goff DC (2000): 
Placebo-controlled trial of glycine added to clozapine in schizophrenia. Am J Psychiatry 157:826-828

Goff DC, Henderson DC, Evins AE, Amico E (1999a): A placebo-controlled crossover trial of D-cycloserine added to clozapine in patients with schizophrenia. Biol Psychiatry 45:512-514

Goff DC, Tsai G, Levitt J, Amico E, Manoach D, Schoenfeld DA, Hayden DL, McCarley R, Coyle JT (1999b): A placebo-controlled trial of D-cycloserine added to conventional neuroleptics in patients with schizophrenia. Arch Gen Psychiatry 56:21-27

Goff DC, Tsai G, Manoach DS, Flood J, Darby DG, Coyle JT (1996): D-cycloserine added to clozapine for patients with schizophrenia. Am J Psychiatry 153:1628-1630

Guo N, Klitenick MA, Tham CS, Fibiger HC (1995): Receptor mechanisms mediating clozapine-induced c-fos expression in the forebrain. Neuroscience 65:747-756

Heresco-Levy U (2000): N-Methyl-D-aspartate (NMDA) receptor-based treatment approaches in schizophrenia: the first decade. Int J Neuropsychopharmacol 3:243-258

Heresco-Levy U, Javitt DC, Ermilov M, Mordel C, Horowitz A, Kelly D (1996): Double-blind, placebo-controlled, crossover trial of glycine adjuvant therapy for treatmentresistant schizophrenia. Br J Psychiatry 169:610-617

Hiroi N, Graybiel AM (1996): Atypical and typical neuroleptic treatments induce distinct programs of transcription factor expression in the striatum. J Comp Neurol 374:70-83

Javitt DC, Zylberman I, Zukin SR, Heresco-Levy U, Lindenmayer JP (1994): Amelioration of negative symptoms in schizophrenia by glycine. Am J Psychiatry 151:1234-1236

Kato A, Ozawa F, Saitoh Y, Fukazawa Y, Sugiyama H, Inokuchi K (1998): Novel members of the Vesl/Homer family of PDZ proteins that bind metabotropic glutamate receptors. J Biol Chem 273:23969-23975

Loscher W, Wlaz P, Rundfeldt C, Baran H, Honack D (1994): Anticonvulsant effects of the glycine/NMDA receptor ligands D- cycloserine and D-serine but not R-(+)-HA966 in amygdala-kindled rats. Br J Pharmacol 112:97-106

MacGibbon GA, Lawlor PA, Bravo R, Dragunow M (1994): Clozapine and haloperidol produce a differential pattern of immediate early gene expression in rat caudateputamen, nucleus accumbens, lateral septum and islands of Calleja. Brain Res Mol Brain Res 23:21-32

Malhotra AK, Pinals DA, Weingartner H, Sirocco K, Missar CD, Pickar D, Breier A (1996): NMDA receptor function and human cognition: the effects of ketamine in healthy volunteers. Neuropsychopharmacology 14:301-307

Merchant KM, Dorsa DM (1993): Differential induction of neurotensin and c-fos gene expression by typical versus atypical antipsychotics. Proc Natl Acad Sci USA 90:3447-3451

Moghaddam B, Adams BW (1998): Reversal of phencyclidine effects by a group II metabotropic glutamate receptor agonist in rats. Science 281:1349-1352

Monahan JB, Handelmann GE, Hood WF, Cordi AA (1989): D-cycloserine, a positive modulator of the N-methylD-aspartate receptor, enhances performance of learning tasks in rats. Pharmacol Biochem Behav 34:649-653

Naisbitt S, Kim E, Tu JC, Xiao B, Sala C, Valtschanoff J, Weinberg RJ, Worley PF, Sheng M (1999): Shank, a novel family of postsynaptic density proteins that binds to the NMDA receptor/PSD-95/GKAP complex and cortactin. Neuron 23:569-582

Olney JW, Newcomer JW, Farber NB (1999): NMDA receptor hypofunction model of schizophrenia. J Psychiatr Res 33:523-533

Paxinos G, Watson C (1986): The Rat Brain in Stereotaxic Coordinates, 2nd ed. New York, Academic Press

Robertson GS, Fibiger HC (1992): Neuroleptics increase c-fos expression in the forebrain: contrasting effects of haloperidol and clozapine. Neuroscience 46:315-328

Robertson GS, Matsumura H, Fibiger HC (1994): Induction patterns of Fos-like immunoreactivity in the forebrain as predictors of atypical antipsychotic activity. J Pharmacol Exp Ther 271:1058-1066

Semba J, Sakai MW, Suhara T, Akanuma N (1999): Differential effects of acute and chronic treatment with typical and atypical neuroleptics on c-fos mRNA expression in rat forebrain regions using non-radioactive in situ hybridization. Neurochem Int 34:269-277

Tu JC, Xiao B, Yuan JP, Lanahan AA, Leoffert K, Li M, Linden DJ, Worley PF (1998): Homer binds a novel prolinerich motif and links group 1 metabotropic glutamate receptors with IP3 receptors. Neuron 21:717-726

van Berckel BN, Evenblij CN, van Loon BJ, Maas MF, van der Geld MA, Wynne HJ, van Ree JM, Kahn RS (1999): D-cycloserine increases positive symptoms in chronic schizophrenic patients when administered in addition to antipsychotics: a double-blind, parallel, placebo-controlled study. Neuropsychopharmacology 21:203-210

Wlaz P, Baran H, Loscher W (1994): Effect of the glycine/ NMDA receptor partial agonist, D-cycloserine, on seizure threshold and some pharmacodynamic effects of MK-801 in mice. Eur J Pharmacol 257:217-225

Young WS 3rd, Bonner TI, Brann MR (1986): Mesencephalic dopamine neurons regulate the expression of neuropeptide mRNAs in the rat forebrain. Proc Natl Acad Sci USA 83:9827-9831 